\title{
MILITARIZAÇÃO E ESCOLA SEM PARTIDO: repercussões no projeto político-pedagógico das escolas
}

\author{
Edileuza Fernandes Silval \\ Ilma Passos Alencastro Veiga ${ }^{2}$ \\ Rosana César de Arruda Fernandes 3
}

\section{RESUMO}

O artigo discute investidas de movimentos conservadores de militarização e Escola sem Partido com o objetivo de refletir acerca de suas repercussões nos projetos político-pedagógicos de escolas públicas. Compreende-se a escola como território em permanente disputa, responsável pela educação formal de crianças, adolescentes e jovens, que realiza um tipo de trabalho sob orientações políticas, ideológicas e econômicas que embasam os arranjos de poder em cada momento histórico. Esse trabalho é sistematizado nos projetos pedagógicos das escolas como expressão de suas finalidades, seu papel social, de definição de estratégias operacionais e ações a serem desenvolvidas coletivamente. No que concerne aos aspectos metodológicos e teóricos, contempla-se: análise de documentos oficiais do governo federal para apreender elementos da realidade situados historicamente e que expressam um projeto de poder assumido pelo grupo dominante no cenário político, e revisão bibliográfica de obras que versam sobre a temática. As discussões sinalizam que a militarização das escolas alinhadas aos ideários da Escola sem Partido repercutem: a) na definição de outra função social para a escola; b) na seleção e controle do saber considerado legítimo e aceitável pelos grupos conservadores; c) no alcance dos objetivos de ensino e aprendizagem previstos nos PPP da escola; d) na relação professor-aluno; e) na fragilização do trabalho colaborativo na escola; f) na autonomia da escola para elaborar, implementar e avaliar seu PPP. Assim, contrariamente à militarização, defende-se a escola, democrática, participativa e colaborativa, que organiza o trabalho pedagógico com respeito à diversidade de sujeitos, às suas experiências e aos valores.

Palavras-chave: Escola pública. Escola sem Partido. Militarização. Projeto políticopedagógico.

\section{Militarization and School without Party: repercussions on the political-}

$$
\text { pedagogical project of schools }
$$

\footnotetext{
ABSTRACT

1 Doutora em Educação. Professora da Universidade de Brasília, Distrito Federal, Brasil. Orcid iD: http://orcid.org/0000-0002-9837-2958. E-mail: edileuzafeunb@gmail.com

${ }^{2}$ Doutora em Educação. Professora da Universidade de Brasília, Distrito Federal, Brasil. Orcid iD: https://orcid.org/0000-0002-0781-4563. E-mail: ipaveiga@terra.com.br

3 Doutora em Educação. Professora da Universidade de Brasília, Distrito Federal, Brasil. Orcid iD: http://orcid.org/ 0000-0002-51 18-1775. E-mail: rosanacarruda@yahoo.com.br
} 
This paper discusses the advances of conservative militarization movements and School without a Party in order to reflect on their repercussions on the politicalpedagogical projects of public schools. School is understood as a territory in constant dispute, responsible for the formal education of children, adolescents, and young people, who carry out a type of work under political, ideological, and economic orientations that support the power arrangements at each historical moment. This work is systematized in the pedagogical projects of schools as an expression of their purposes, their social role, of defining operational strategies and actions to be developed collectively. As for the methodological and theoretical aspects, it contemplates: analysis of official documents of the federal government to apprehend elements of reality situated historically and that express a power project assumed by the dominant group in the political scenario; and bibliographic revision of works that deal with the issue. The discussions signal that the militarization of schools aligned with the ideals of the School without a Party impacts: a) on the definition of another social function for the school; b) on the selection and control of knowledge considered legitimate and acceptable by conservative groups; c) on the achievement of teaching and learning goals foreseen in the school's PPPs; d) on the teacher-student relationship; e) on the weakening of collaborative work in the school; f) on the autonomy of the school to elaborate, implement and evaluate its PPP. Thus, contrary to militarization, democratic, participatory and collaborative school is defended, organizing pedagogical work with respect to the diversity of subjects, their experiences and values.

Keywords: Public school. School without a Party. Militarization. Political-pedagogical project.

\section{Militarización y Escuela sin Partido: repercusiones en el proyecto político- pedagógico de las escuelas}

\section{RESUMEN}

El artículo analiza los embates de los movimientos de militarización conservadora y de la Escuela sin Partido para reflexionar sobre sus repercusiones en los proyectos político-pedagógicos de las escuelas públicas. Se entiende por escuela un territorio en permanente disputa, responsable de la educación formal de niños, adolescentes y jóvenes, que realizan un tipo de trabajo bajo los lineamientos políticos, ideológicos y económicos que sustentan los arreglos de poder en cada momento histórico. Este trabajo se sistematiza en los proyectos pedagógicos de las escuelas como expresión de sus propósitos, su papel social, la definición de estrategias operativas y acciones a desarrollar colectivamente. En cuanto a los aspectos metodológicos y teóricos, incluye: el análisis de los documentos oficiales del gobierno federal para captar elementos de la realidad situados históricamente y que expresan un proyecto de poder asumido por el grupo dominante en el escenario político; y la revisión bibliográfica de los trabajos sobre el tema. Los debates señalan que la militarización de las escuelas alineadas con los ideales de la Escuela sin Partido repercute: a) en la definición de otra función social para la escuela; b) en la selección y el control de los conocimientos considerados legítimos y aceptables por los grupos conservadores; c) en el logro de los objetivos de enseñanza y aprendizaje previstos en los PPP de la escuela; d) en la relación profesor-alumno; e) en el debilitamiento 
del trabajo de colaboración en la escuela; f) en la autonomía de la escuela para elaborar, aplicar y evaluar su PPP. Así, contrariamente a la militarización, se defiende la escuela democrática, participativa y colaborativa, que organiza el trabajo pedagógico con respeto a la diversidad de los sujetos, sus experiencias y valores.

Palabras clave: Escuela pública. Escuela sin Partido. Militarización. Proyecto políticopedagógico.

\section{INTRODUÇÃO}

A aprovação do Plano Nacional de Educação 2014-2024 (PNE) gerou expectativas na comunidade educacional brasileira acerca de sua implementação tendo em vista a redução da desigualdade e inclusão de minorias, valorização da profissão docente, efetivação da gestão democrática e financiamento da educação pública.

No entanto, há quatro anos para o cumprimento do Plano, o que se tem são ações políticas da União, estados e municípios na contramão do que estabelece a Meta 19 do PNE de incentivo à gestão democrática da educação e sua efetivação. Essa deveria estar associada a critérios técnicos de mérito e desempenho e à consulta pública à comunidade escolar, no âmbito das escolas públicas, prevendo recursos e apoio técnico do Estado.

De acordo com a Lei de Diretrizes e Bases da Educação Nacional (LDBEN), Lei nos 9.394 de 1996, as instituições públicas que ofertam a educação básica devem ser administradas com base no princípio da gestão democrática. Entende-se que um dos mecanismos para a garantia desse princípio é a elaboração de forma participativa com toda a comunidade escolar dos projetos pedagógicos. Esses expressam a autonomia pedagógica, administrativa, financeira e jurídica para a tomada de decisões acerca das finalidades educativas que caracterizem a identidade de cada instituição. Nesse sentido, tem-se, no artigo 12, inciso I da Lei, que "os estabelecimentos de ensino, respeitadas as normas comuns e as do seu sistema de ensino, terão a incumbência de: I - elaborar e executar sua proposta pedagógica." 
Dentre as ações do atual contexto político e educacional que confrontam a gestão democrática da educação, destaca-se a expansão do modelo de militarização das escolas públicas brasileiras regulamentado pelo Decreto no 9.665 em 2019. Essa normativa prevê, no seu artigo 11, inciso XVI, a promoção progressiva de escolas cívico-militares "tendo como base a gestão administrativa, educacional e didático-pedagógica adotada por colégios militares do Exército, Polícias e Bombeiros Militares" (BRASIL, 2019). Destaca-se também, embora sem regulamentação legal, as constantes investidas do movimento idealizado no início dos anos 2000, denominado "Escola sem Partido", propalado como de natureza "apartidária", com o argumento de representar pais e estudantes contrários ao que seus integrantes caracterizam como "doutrinação ideológica" nas escolas.

Em face dessas considerações iniciais, objetiva-se neste artigo refletir acerca das implicações dessas propostas conservadoras nos projetos políticopedagógicos (PPP) das escolas públicas, território em permanente disputa. Para isso, recorre-se a documentos oficiais do governo federal para apreender elementos da realidade situados historicamente e que expressam um projeto de poder assumido pelo grupo dominante no cenário político, bem como à revisão bibliográfica de produções que versam sobre a temática e constituem fontes reveladoras das disputas em torno do projeto de escola pública.

A proposição de análise crítica dos dados sustenta-se no pressuposto de que o modelo de militarização de escolas articulado ao movimento Escola sem Partido confronta a autonomia garantida em lei às instituições para elaborar, desenvolver, acompanhar e avaliar os seus projetos políticopedagógicos4. Com esse intento, são produzidos diagnósticos por meio das avaliações externas ${ }^{5}$ nacionais e internacionais, identificando problemas de

\footnotetext{
4 Embora a LDBEN denomine proposta pedagógica, neste artigo adota-se projeto políticopedagógico com respaldo em Veiga (1996).

5 Resultado do Pisa de 2015 é tragédia para o futuro dos jovens brasileiros, afirma ministro. Disponível em: http://portal.mec.gov.br/component/content/article?id=42741. Acesso: 26 ago. 2020.

Dados do Saeb 2017 mostram que o ensino fundamental avançou, mas o ensino médio segue estagnado. Disponível em: https://gl.globo.com/educacao/noticia/2018/08/30/7-de-
} 
gestão escolar, currículo, disciplina, formação docente para construir o senso comum de que a escola pública está em crise, não funciona e requer intervenções do Estado por meio de mecanismos de controle e regulação.

Nega-se, assim, o potencial das escolas e dos profissionais da educação na tomada de decisões visando à resolução de problemas escolares, afrontando a sua autonomia pedagógica e política para conceber e implementar um projeto de escola pública democrático e participativo.

\section{Escola: território em disputa}

Parte-se do pressuposto de que a escola é território em disputa, sendo seus sentidos, significados, finalidades imbricados em estruturas de poder. No Dicionário Houaiss da Língua Portuguesa (2001, p. 429), território é "área de um distrito, município, cidade, país, etc. Extensão geográfica do Estado sobre a qual ele exerce a sua soberania". A soberania diz que é uma autoridade suprema aquela que detém o poder sobre outros que não o detêm (Idem, p. 409). Nessa perspectiva, "o território tem uma ocupação, e essa revela intencionalidades: a favor de que e contra o que se posiciona" (CUNHA, 2008, p. 185). Inconcebível, portanto, reconhecer territórios neutros, e ocupá-los pressupõe confrontação de forças. Que território é a escola pública?

A escola pública foi instituída no final do século XVIII numa perspectiva revolucionária, operada pela burguesia na condição de classe emergente, inspirada pelos ideários adotados a partir da revolução francesa (SAVIANI, 2007). A sua institucionalização vincula-se ao processo de surgimento da sociedade de classes desde a origem com objetivos diferenciados no que concerne ao atendimento dos membros das diferentes classes. A divisão dos homens em classes fez com que o conhecimento também passasse a ser dividido conforme o papel que cada classe social desempenha na sociedade.

cada-10-alunos-do-ensino-medio-tem-nivel-insuficiente-em-portugues-e-matematica-dizmec.ghtml. Acesso: 26 ago. 2020. 
Assim, historicamente, a educação se configura pela dualidade. Para os membros da classe proprietária dos meios de produção, a educação é "centrada nas atividades intelectuais, na arte da palavra e nos exercícios físicos de caráter lúdico ou militar" (Idem, p. 175), enquanto que, para os não proprietários, sua centralidade está no processo de trabalho. A origem da escola vincula-se à primeira modalidade, de maneira que o processo de divisão dos homens em classe resulta na divisão da educação. Aquela destinada à classe dominante diferencia-se da que os membros da classe dominada terão acesso. Isso nos provoca a pensar se a organização escolar militarizada e as imposições do movimento que defende a escola sem partido serão adotadas pelas instituições de ensino privadas, tendo em vista o seu papel de garantir, por meio da educação e do conhecimento, a perpetuação de valores, ideias e interesses de grupos socialmente privilegiados.

A despeito de críticas em relação a sua dinâmica organizacional, suas práticas pedagógicas, seus processos, sua estrutura física e material, o fato é que a escola é um espaço reconhecidamente de relevância social, responsável pela educação formal de crianças, adolescentes e jovens, promotora da produção e preservação do patrimônio cultural da humanidade e da humanização dos sujeitos. O seu trabalho resulta de orientações políticas, ideológicas e econômicas que embasam os arranjos de poder em cada momento histórico, "em diferentes nações e regiões a articulação da escola com as demandas sociais se dá sempre de uma forma singular" (ALVES, 2005, p. 52). Em face disso, problematiza-se se estariam incluídas, entre as demandas da sociedade no século XXI, a padronização de comportamentos dos estudantes por meio da retomada da pedagogia comportamental de base tecnicista, predominante nos anos de ditadura militar no Brasil.

Historicamente, as disputas em torno da educação e da escola são vinculadas aos ditames do trabalho explorado que dinamiza o capital. Para isso, o projeto educacional visa à reprodução de uma ordem que tem se efetivado pela seleção ou até mesmo negação do conhecimento escolar 
"que revela as determinações do real em suas múltiplas dimensões, acoplada à manipulação ideológica das consciências, com vistas à naturalização da exploração" (JIMENEZ et al., 2007, p. 3). Nessa direção, as abordagens de movimentos em defesa da militarização e de uma "escola sem partido" (como se o apartidarismo fosse possível) emergem do receio quanto ao inegável potencial da escola de se constituir espaço democrático de organização de grupos sociais desprivilegiados, e que pode resultar em tomada de consciência da real condição dos alunos como sujeitos expropriados de bens materiais e de direitos, dentre os quais, o direito a educação de qualidade.

Compreender esse processo de manipulação ideológica por meio de ações políticas como militarização de escolas e Escola sem Partido conduz ao reconhecimento da educação como prática social, fortemente identificada com o processo de trabalho. Essa é uma ação transformadora do homem sobre a natureza para atender às suas necessidades e garantir sua existência humana. Produto do trabalho, "o homem não nasce homem. Ele forma-se homem. Ele não nasce sabendo produzir-se como homem. Ele necessita aprender a ser homem, precisa aprender a produzir sua própria existência" (SAVIANI, 2007, p. 154). Essa produção é possível em processos educativos, o que demonstra que a origem da educação coincide com a do próprio homem (Idem), evidenciando a determinação entre trabalho e educação, atividades especificamente humanas.

Em um contexto de profunda crise estrutural do capital, Mészáros (2011, p. 17) previu que esta afetaria "não apenas o mundo das finanças globais mais ou menos parasitárias, mas também todos os domínios da nossa vida social, econômica e cultural". Suas previsões se confirmam em ações políticas no campo da vida educacional empreendidas por grupos conservadores que atribuem à educação e à escola o poder de resolver os males que afetam a sociedade, até mesmo, a violência.

Nesse cenário de crise, intensifica-se o trabalho explorado que subjuga um exército de trabalhadores submetidos à precarização e à flexibilização de 
atividades 6 . Ao mesmo tempo, acirram-se interesses políticos e econômicos que embasam ações como a militarização de escolas públicas localizadas em territórios socialmente vulneráveis. Nesse bojo, a educação é anunciada e denunciada como a causa e a solução dos problemas, como se apreende pelo discurso de que a militarização das escolas resolverá a insegurança e a indisciplina em seu interior (MENDONÇA, 2019; LACÉ et al., 2019). Não se reconhece que a violência é produzida socialmente, uma vez que há múltiplas determinações, como $\circ$ elevado número de pessoas desempregadas7; a ausência do Estado no cumprimento de suas responsabilidades e de políticas públicas para atender a grupos sociais economicamente desprivilegiados. Esse discurso encontra respaldo nas famílias $^{8}$, naturalmente preocupadas com a segurança de seus filhos e convencidas de que a escola pública é ineficaz e violenta.

Retoma-se, assim, a ideação de escola como território "mediado pelas representações construídas por um determinado grupo ao estabelecer seu poder frente a outro e que se apropria do espaço como forma de sua expressão e projeção" (LOPES, 2007, p. 80). Para isso, são adotados projetos de manipulação ideológica das consciências com o propósito de transmitir valores, atitudes, comportamentos, conhecimentos, ideias, de acordo com os interesses de grupos. Assim, a educação alinha-se à manutenção da ordem social vigente.

Nessa totalidade social e educacional, de intensos e recorrentes questionamentos sobre a escola e seus resultados, cresce a investida pela regulação da educação pela avaliação externa a partir de critérios ligados

6 O ensino a distância é uma das formas de manifestação da flexibilização do trabalho. Ver KUENZER, A. Z. Trabalho e escola: aprendizagem flexibilizada. In: Reunião Científica Regional da ANPED: Educação, movimentos sociais e políticas governamentais. Curitiba, julho, 2006, p. 1-22.

7 A taxa de desemprego subiu para 13,3\% no segundo trimestre de 2020, atingindo o maior nível em três anos (Instituto Brasileiro de Geografia e Estatística). Disponível em: https://www.ibge.gov.br/. Acesso em: 21 ago. 2020.

8 Pais aprovam modelo de militarização de escolas do DF. Disponível em https://www.metropoles.com/distrito-federal/educacao-df/pais-aprovam-modelo-demilitarizacao-de-escolas-do-df-sinpro-e-contra. Acesso em 07 set. 2020. 
ao controle dos processos que se integram para a produção, circulação, troca e consumo de produtos e serviços (FREITAS, 2018). Isso impõe um tipo de educação voltada à formação do trabalhador flexível, em atendimento à reestruturação produtiva (ANTUNES, 2000).

Para desqualificar a escola pública são usados resultados de avaliações externas fixadas por padrões internacionais e índices de qualidade definidos pela Organização para a Cooperação e Desenvolvimento Econômico (OCDE), pelo Fundo Monetário Internacional (FMI) e pela Organização das Nações Unidas para a Educação, a Ciência e a Cultura (UNESCO). A legitimação desses organismos em suas teses faz operar a lógica do "mercado" na elaboração de políticas públicas, ressignificando as relações do Estado com a sociedade civil, instrumentos da hegemonia neoliberal.

Assim, sob os ditames do capital, o Estado defende propostas que visam homogeneizar a formação e os comportamentos dos estudantes, controlando seus corpos e mentes visando "equacionar a contradição educar/explorar tentando controlar mais diretamente $\bigcirc$ aparelho educacional e impondo seu projeto político" (FREITAS, 2005, p. 128) conservador com predomínio de uma racionalidade econômica. Nesse sentido, Apple (2003) chama a atenção para um processo de "economização" do projeto educacional caracterizado pela sua despolitização. Entende-se que os movimentos de militarização e da Escola sem Partido são expressão desse processo.

Destaca-se que, diante da universalização do Ensino Fundamental e do Ensino Médio, caracterizando-os como espaços das diversidades, de culturas, de histórias, de singularidades, é necessário repensar a organização escolar. É real o desafio de melhorar a qualidade da educação básica pública para reverter os elevados índices de evasão e reprovação, revelados pelos dados do Censo Escolar 20199 do Ministério da Educação. No entanto, advoga-se a qualidade referenciada socialmente, que não se sustenta em

9 Censo Escolar. Disponível em: http://portal.inep.gov.br/censo-escolar. Acesso em: 19 ago. 2020. 
ideias de eficiência e produtividade de base empresarial, vinculada a "uma noção produtivista de resultados e firmada nos parâmetros da razão instrumental e calculista que constituem a base do sistema sociometabólico do capital" (SOUZA, 2010, p. 66). Essa perspectiva confronta a concepção que aqui se defende, de qualidade negociada que

não é um dado de fato, não é um valor absoluto, não é adequação a um padrão ou a normas estabelecidas a priori e do alto. Qualidade é transação, isto é, debate entre indivíduos e grupos que têm um interesse em relação à rede educativa, que têm responsabilidade para com ela, com a qual estão envolvidos de algum modo e que trabalham para explicitar e definir, de modo consensual, valores, objetivos, prioridades, ideias sobre como é a rede [...] e sobre como deveria ou poderia ser (BONDIOLI, 2004, p. 14).

Esse pacto pela qualidade da educação é possível com a participação democrática da comunidade escolar na tomada de decisões, mecanismo ético e dialógico com os atores internos e externos à escola, para definição do projeto de educação que almejam. Isso passa necessariamente pelo cumprimento do que prevê a Constituição Federal de 1988, em seu artigo 205, que trata da colaboração da sociedade para a promoção da educação visando ao pleno desenvolvimento da pessoa, seu preparo para o exercício da cidadania e sua qualificação para o trabalho.

Assim, para compreender os impactos da militarização e das ideias defendidas pelo Movimento Escola sem Partido na organização do trabalho pedagógico da escola, discutem-se a seguir os interesses e ideologias que embasam essas propostas.

\section{Movimento Escola sem Partido e militarização de escolas: a quem interessa?}

O período de 2016 a 2020 caracteriza-se por medidas estratégicas restritivas dos direitos sociais. No movimento do impeachment da Presidenta Dilma Rousseff, ao ser empossado seu vice-presidente, Michel Temer, foram adotadas políticas de cortes orçamentários da educação que repercutiram 
no congelamento de gastos federais por $20 \operatorname{anos}^{10}$. Os ataques aos direitos sociais têm se intensificado no governo de Jair Bolsonaro, ao mesmo tempo em que são impostas reformas no campo da educação que inviabilizam as metas do Plano Nacional de Educação - 2014-2024.

Nesse cenário, a difusão de outras perspectivas de escolarização reverte o papel social da escola, de instituição pública, laica, democrática, para uma escola repressora pautada pela neutralidade científica. Uma dessas perspectivas é identificada pelo Movimento Escola sem Partido, que se intitula apartidário, mas apresenta forte vínculo com partidos políticos, cujos filiados compõem a denominada "bancada da bíblia". Em estudo sobre as redes da Escola sem Partido, Espinoza e Queiroz (2017) enfatizam que o "apartidarismo se entenderia de forma literal como uma ausência de subordinação dos interesses da Escola sem Partido frente aos partidos políticos, organizações da sociedade civil, grupos econômicos de natureza religiosa" (2017, p. 54). No entanto, enfatizam as fortes conexões de seus integrantes com grupos religiosos.

Em 2016, o Partido da República (PR) apresentou no Senado Federal o Projeto de Lei n 193/2016, de autoria do Senador Magno Pereira Malta, do Estado do Espírito Santo, com vista à inclusão na Lei de Diretrizes e Bases da Educação Nacional (LDBEN) dos preceitos defendidos pelo movimento Escola sem Partido. Esse movimento ganhou capilaridade, de maneira que, em dezenove estados, diversos municípios e no Distrito Federal, projetos de igual teor foram apresentados. Conforme Guilherme e Picoli $(2018$, p. 3) isso ocorreu

a despeito de ter sido considerado, em nota técnica, inconstitucional pela Procuradoria Federal dos Direitos do Cidadão do Ministério Público Federal (2016), de decisão liminar em mesmo sentido do Ministro Roberto Barroso do Supremo Tribunal Federal para a Ação Direta de Inconstitucionalidade $n^{\circ} 5537$ (STF, 2017) e de ter sido julgado como um plano que nega a produção acadêmica e os avanços legais das últimas décadas, além de antidemocrático e criminalizador do trabalho docente por várias associações de

10 Ver Emenda Constitucional $n^{\circ} 95$ de 15 de dezembro de 2016. BRASIL. Disponível em: https://www2. camara.leg.br/legin/fed/emecon/2016/emendaconstitucional-95-15dezembro-2016-784029-publicacaooriginal-151558-pl.html. Acesso: 25 ago. 2020. 
pesquisa, dentre as quais destacam-se a Associação Nacional de Pesquisa em Educação (ANPED, 2016) e a Associação Brasileira de Ensino de História (ABEH, 2015).

O Programa Escola sem Partido, como afirmam Guilherme e Picoli, foi criado para dar visibilidade ao que seus defensores consideram um problema das instituições educativas: "a instrumentalização do ensino para fins políticos, ideológicos e partidários" (2018, p. 3). Isso é uma contradição, uma vez que, dentre os integrantes desse movimento, há representantes de partidos políticos e de grupos religiosos. O que propõem ameaça os princípios de respeito à liberdade e à solidariedade humana, do pluralismo de ideias e de concepções pedagógicas, da valorização profissional, da igualdade de condições de acesso e permanência na escola, da garantia do padrão de qualidade elencados no art. $3^{\circ}$ da LDBEN de 1996.

Os Projetos de Lei $n^{\circ} 867 / 2015^{11}$ e $n^{0} 193 / 2016^{12}$ pautam-se pela "compreensão de que a escola deve limitar sua atuação na instrução e instrumentalização, na transmissão de conhecimentos" (GUILHERME; PICOLI 2018 , p. 4). Entretanto, ao mesmo tempo em que se defende a neutralidade dos conteúdos curriculares, enfatiza-se a difusão de valores religiosos e de doutrinação, tendo por base a política conservadora, ideológica, neoliberal que desqualifica o trabalho docente e a formação de crianças e jovens. A esse respeito, Apple chama a atenção ao fato de que os neoconservadores tomam para si a autoridade para definir os saberes considerados legítimos e culturalmente superiores, "arquétipos da 'tradição' para todos" (2003, p. 59). No Brasil, a pressão exercida pelo governo federal desde 2016 para a definição de uma base comum nacional para a educação básica expressa a força desse grupo na defesa de um currículo nacional sob o argumento de melhoria da qualidade da educação. Na verdade, propõe um currículo

11 CÂMARA DOS DEPUTADOS. Projeto de Lei n. 867/2015. Disponível em: <Disponível em: http://www.camara.gov.br/proposicoesWeb/fichadetramitacao?idProposicao=1050668 >. Acesso em: 04 set. 2020.

12 SENADO FEDERAL. Projeto de Lei do Senado, 193 de 2016. <Disponível em: https://www25.senado.leg.br/web/atividade/materias/-/materia/125666. Acesso em 07 set. 2020. 
parametrizado por avaliações externas, mecanismos de controle sobre o "saber oficial", como define Apple (Idem).

Com o mesmo alinhamento ideológico e teórico do movimento Escola sem Partido, a militarização das escolas públicas brasileiras tem avançado antes mesmo da publicação do Decreto n 9.665 em 2 de janeiro de 2019, que institui o Programa Nacional das Escolas Cívico-Militares (PECIM) com a promoção progressiva de escolas dessa natureza em todo o país. O Decreto respalda-se na defesa do modelo de escolas cívico-militares como mecanismo para resgatar valores no ambiente escolar e resolver problemas disciplinares e de segurança com adesão voluntária, preferencialmente para as instituições de Ensino Fundamental e Médio consideradas vulneráveis socialmente. Até setembro de 2019, 650 municípios e dezesseis unidades da federação, incluindo o Distrito Federal haviam aderido ao Programa do governo federal. A meta é implementar 216 escolas até 202313.

Entende-se que o ideário conservador da Escola sem Partido potencializa o avanço da militarização, caracterizando-os como facetas de um projeto conservador e homogeneizante para consolidação de uma educação alienante assumida por governos de orientação ideológica conservadora nas esferas federal, estadual, municipal e distrital.

As justificativas dos governos para militarizar escolas são apelativas, quase sempre vinculadas ao combate à violência no interior das escolas. $\mathrm{Na}$ análise de Fernandes Silva e Silva (2019), esse modelo de gestão escolar desconsidera que o fenômeno da violência é estrutural e consequência da desigualdade social e econômica no Brasil, que leva ao empobrecimento da população sem acesso a empregos que, quando a ele tem acesso, é de forma precarizada, com más condições de trabalho, baixos salários, pouca segurança e alta rotatividade dos postos de trabalho como complementam Brito e Rezende (2019).

13 Cerca de 650 municípios manifestaram interesse em implantar escolas cívico-militares Disponível em: http://portal.mec.gov.br/component/content/article?id=81311. Acesso: 18 out. 2020. 
As escolas militarizadas na esteira desse movimento conservador diferem de escolas militares que têm sua origem na Real Academia de Marinha, criada em 1808 e na Real Academia Militar, criada em 1810, por D. Milton Vl, para formação de oficiais de infantaria, cavalaria e artilharia, engenheiros, geógrafos e topógrafos e de um exército capaz de proteger a costa brasileira de invasões, bem como para o aprimoramento do Corpo de Tropas (NOGUEIRA, 2014). No Brasil, há treze instituições escolares militares geridas pelo Exército Brasileiro e identificadas pelo rigor, disciplina e "qualidade de ensino"14. As vagas nelas ofertadas são concorridas, os estudantes são preparados para tirar boas notas no Exame Nacional do Ensino Médio (Enem) e obter aprovação nos principais vestibulares do País.

Há ampla divulgação de que essas escolas, mantidas pelo Exército Brasileiro, são melhores do que as escolas públicas das redes estadual e municipal. O que não se propaga é o que essas instituições recebem em verbas ${ }^{15}$ para investir em infraestrutura e na qualidade do corpo docente. Cada aluno custa três vezes mais se comparado aos estudantes das demais escolas públicas; os professores recebem melhores salários; as escolas dispõem de laboratórios equipados e os estudantes recebem todo o suporte didático-pedagógico, além de serem selecionados a partir de critérios que excluem os que não se encaixam nos padrões estabelecidos.

$\mathrm{Na}$ comparação entre as escolas militares e as públicas regulares estaduais, municipais ou distritais não são feitas distinções em relação ao financiamento, custo por aluno ${ }^{16}$, estrutura física e material das escolas e

${ }^{14}$ Conheça os treze Colégios Militares. Disponível em: http://www.eb.mil.br/web/ingresso/colegios-militares/-

Lasset_publisher/8E9mFznTIAQW/content/conheca-os-12-colegios-militar-1. Acesso em: 21 ago. 2020.

15 De acordo com reportagem do Jornal Estadão, estudantes de colégios militares custam três vezes mais ao País. Disponível em: https://politica.estadao.com.br/noticias/eleições.estudantes-de-colegio-militar-custam-tresvezes-mais-ao-pais. Acesso em: 21 ago. 2020.

16 Em colégio militar, aluno custa 3 vezes mais do que na rede pública. Disponível em https://br.financas.yahoo.com/noticias/em-colegio-militar-aluno-custa-3-vezes-mais-que-narede-publica-164635953.html. Acesso em: 04 set. 2020. 
condições de trabalho dos professores. Dados do Censo Escolar de 201917 indicam que apenas $44,1 \%$ das escolas públicas têm laboratório de ciências; $87,5 \%$ de todas as escolas de ensino médio têm biblioteca; e $78,1 \%$, laboratório de informática. Esses dados revelam a desigualdade nas condições de aprendizagem para os estudantes da escola pública que afetam os seus projetos pedagógicos com vistas ao cumprimento das finalidades constitucionais da educação.

\section{Militarização e Escola sem Partido: repercussões no projeto político- pedagógico de escolas públicas}

Em continuidade às reflexões propostas neste artigo, parte-se do pressuposto de que estamos diante de um embate entre "projetos antagônicos do ponto de vista conceitual e das práticas" como discutem as pesquisadoras Fernandes Silva e Silva (2019, p. 50) ao analisarem a implementação da militarização de escolas públicas no Distrito Federal.

No atual cenário de expansão de escolas militarizadas no Brasil, como indicam Lacé et al. (2019), tem-se, de um lado, um projeto conservador que representa os interesses de grupos hegemônicos (políticos, econômicos, culturais e religiosos), que visam o controle ideológico da educação e transformá-la em negócio rentável. De acordo com Apple, os movimentos conservadores se conectam a ideia de que "somente por meio dos mercados e de um retorno a um passado edênico as escolas, nossos filhos e nossa própria nação podem ser "salvos'" (2003, p. 34). Talvez por isso, os critérios de escolha de escolas a serem militarizadas sejam a violência interna e os índices de desempenho gerados pelos resultados das avaliações externas.

De outro lado, tem-se o projeto político-pedagógico (PPP) da escola, documento em permanente construção, sistematizador do seu trabalho

\footnotetext{
17 Resultados finais do censo escolar 2019 http://portal.mec.gov.br/index.php?option=com_content\&view=article\&id=8401 1 :inepdivulga-resultados-finais-do-censo-escolar-2019\&catid=211. Acesso em: 04 set. 2020.
} 
pedagógico, processo fundado na busca pelas unidades teoria-prática, objetivo-avaliação, conteúdo-forma, professor-aluno, ensino-aprendizagem. O PPP é a sistematização da práxis educativa que se concretiza pelo trabalho pedagógico e que, conforme Veiga,

Ao se constituir em processo participativo de decisões, preocupa-se em instaurar uma forma de organização do trabalho pedagógico que desvele os conflitos e as contradições, buscando eliminar as relações competitivas, corporativas e autoritárias, rompendo com a rotina do mando pessoal e racionalizado da burocracia e permitindo relações horizontais no interior da escola (2004, p. 32).

Nessa perspectiva, o PPP exige reflexão crítica sobre as finalidades da educação e da escola e sobre sua função social, questões fundantes para a definição de estratégias operacionais e ações a serem desenvolvidas coletivamente. Para isso, é necessário compreender que o trabalho coletivo implica problematizar e repensar concepções, práticas e processos no trabalho pedagógico com vistas à qualidade social/negociada da educação (BONDIOLI, 2004).

Considera-se trabalho pedagógico

todo o trabalho cujas bases estejam, de alguma forma, relacionadas à pedagogia, evidenciando métodos, técnicas, avaliação intencionalmente planejadas e tendo em vista $O$ alcance de objetivos relativos à produção de conhecimentos (FERREIRA, 2010, p. 1).

No contexto escolar e de sala de aula e que ocorre na e pela relação professor-aluno. Esses são protagonistas da ação educativa que desenvolvem atividades intencionais e planejadas visando o alcance dos objetivos e intencionalidades do PPP da escola.

Nesse processo, não se pode desconsiderar as determinações sociais, econômicas, históricas, culturais, políticas e da própria instituição escolar sobre o trabalho e a gestão escolar. As ideias e ações de grupos no poder para implementar projetos conservadores de ensinar, aprender e avaliar são algumas dessas determinações que repercutem no projeto pedagógico das escolas, especificamente nos elementos que $O$ constitui alguns contemplados a seguir: 
a) A função social da escola, expressa no projeto, em torno da qual as instituições educativas se organizam para garantir à sociedade 0 acesso ao conhecimento escolar é alterada tendo em vista a adequação do PPP à lógica organizacional dos quartéis cuja disciplina rígida e repetitiva visa preparar sujeitos obedientes e subordinados às normas e regras. Com essas práticas, as escolas vivenciam "um novo tipo de controle que se organiza em torno da gestão da vida e se exerce pelo engendramento de técnicas disciplinares aos dispositivos de segurança" (BRITO e REZENDE, 2019, p. 844). Altera-se a função da escola/educação prevista constitucionalmente, reconfigurando os sentidos e significados dos PPP para toda a comunidade escolar.

b) Os conhecimentos escolares são impactados em relação ao conteúdo e à forma de tratamento. Isso porque são recorrentes as tentativas dos neoconservadores (Escola sem Partido) de recuperar um passado edênico e o saber tradicional (APPLE, 2003) considerado legítimo e aceitável nos currículos escolares. Ao mesmo tempo, buscam exercer o controle sobre conteúdos relacionados às questões de gênero, raça, sexualidade, multiculturas, considerados perniciosos às crianças e jovens. Assim, os projetos conservadores vão criando exigências, caracterizando um processo de "aprisionamento das escolas" (FREITAS, 2018) em que os estudantes podem ser os mais afetados pelo intenso controle de suas mentes e corpos regulamentado em normas e regras de comportamentos, limites à expressão, restrições quanto a vestimentas, ornamentos e estilos de cabelos e, consequente, aligeiramento da formação pelo esvaziamento dos currículos escolares. Aos grupos sociais menos favorecidos economicamente defende-se uma formação utilitária, aligeirada, alienante, orientada pelo mercado. Exemplo dessa investida foi a aprovação de currículo nacional por meio da instituição de base nacional comum para a educação básica à revelia dos PPP das escolas. 
c) O ensino-aprendizagem pode ser afetado para atender às normas que reforçam a função disciplinar da escola e que tem no professor o mediador dessas normas no contexto de sala de aula. De acordo com Postic, dessa forma, "o docente pode acentuar voluntariamente a parte das coações para reduzir a parte da iniciativa e da responsabilidade dos alunos" (1990, p. 165) o que, sem dúvida, repercute no processo formativo e na construção da autonomia dos estudantes para atuarem como copartícipes do processo ensino-aprendizagem.

d) A relação professor-aluno caracteriza-se pelas relações interpessoais construídas no e pelo trabalho pedagógico entre professores e alunos e entre esses e seus pares. Nessas relações se realizam interações e comunicações por meio de atividades orientadas à construção de conhecimentos, significados, valores, atitudes e vínculos (PATTO, 1997; POSTIC, 1990). Professores cuja autonomia didático-pedagógica é desrespeitada tendem a reproduzir essas situações com os estudantes interferindo na qualidade das relações e, consequentemente, no desenvolvimento dos alunos. Além disso, a militarização abre as portas das escolas para profissionais sem formação específica e pedagógica para a docência, podendo impactar na consecução dos objetivos de ensino e aprendizagem previstos nos PPP das escolas.

e) $O$ trabalho colaborativo na escola pode ser comprometido tendo em vista que se concretiza em equipe, pares, conselhos, colegiados, como alternativa ao isolamento profissional e ao trabalho individualizado no contexto escolar (FULLAN e HARGREAVES, 2006), o que não se observa no modelo de Escola sem Partido. Trabalhar colaborativamente requer de equipes gestoras e pedagógicas ações voltadas à formação de grupos, à elaboração de projetos que contribuam para 0 alcance de objetivos, metas e finalidades educativas. Contrárias a essa lógica, as relações marcadas pela vigilância e controle podem reforçar o 
isolamento profissional e o trabalho individual desmobilizador que, em certa medida, contribuem para a implementação de um projeto conservador de escola.

f) A autonomia das escolas é prevista no artigo 15 da LDBEN que garante às escolas públicas de educação básica, "progressivos graus de autonomia pedagógica, administrativa e de gestão financeira, observadas as normas gerais de direito financeiro público" (BRASIL, 1996), e no artigo 14, que garante a participação dos profissionais da educação na elaboração do projeto pedagógico da escola. Essas previsões legais são desrespeitadas com o projeto de militarização que compartilha a gestão da escola com profissionais de corporações militares. É com base na autonomia garantida em lei que a escola exercita o seu potencial de pensar um projeto educativo com ações para o enfrentamento de conflitos disciplinares, da evasão e da reprovação, e de busca de condições didático-pedagógicas promotoras da aprendizagem.

De acordo com Lima (2002, p. 7), em processos democráticos, em que a escola exerça sua autonomia pode-se "assegurar o desenvolvimento profissional dos docentes ao longo da carreira, a aprendizagem de excelência para os alunos e a transformação das escolas em autênticas comunidades de aprendizagem". São essas comunidades que favorecem o cumprimento das finalidades educativas.

Em face dessas análises, afirma-se que o PPP das escolas militarizadas orienta-se pela concepção tecnicista/neotecnicista. Trata-se de um projeto de gestão empresarial para cumprir normas técnicas e burocráticas por meio da racionalização do trabalho pedagógico (VEIGA, 2019) distante dos fundamentos políticos e socioculturais que embasam os projetos democráticos e participativos. A esse respeito Freitas $(2012$, p. 383) esclarece que:

[...] O tecnicismo se apresenta, hoje, sob a forma de uma "teoria da responsabilização", meritocrática e gerencialista, onde se propõe a mesma racionalidade técnica de antes na forma de "standards", ou 
expectativas de aprendizagens medidas em testes padronizados, com ênfase nos processos de gerenciamento da força de trabalho da escola (controle pelo processo, bônus e punições), ancorada nas mesmas concepções oriundas da psicologia behaviorista, fortalecida pela econometria, ciência da informação e de sistemas, elevadas à condição de pilares de educação contemporânea (grifos das autoras).

Nessa perspectiva, a militarização escolar articula-se aos ideários da Escola sem Partido como partes de um projeto reformista e mercantilista que passa a orientar políticas públicas educacionais com o intuito de

reparação da desordem e da violência que reina na sociedade. É preciso considerar que a polícia é chamada para impedir a violência na escola é a mesma que não consegue entregar resultados à sociedade em relação às políticas públicas de segurança para os quais ela efetivamente foi criada e existe. (MENDONÇA, 2019, p. 607).

As normas rígidas de disciplina violentam a própria individualidade e negam $\mathrm{o}$ direito à diversidade de crianças e adolescentes (Idem). A presença de militares armados nas escolas, alternativa apresentada pelos governos para solucionar problemas disciplinares, demarca um tipo de projeto pedagógico calcado na obediência, na subordinação e na submissão por profissionais e estudantes à hierarquia militar.

Em face disso, questiona-se como garantir às escolas a construção de seus projetos político-pedagógicos como documento de identidade, expressão de sua autonomia. A forma açodada de implantação da militarização em redes de ensino dos estados e municípios evidencia tratarse de um projeto educacional em ascensão no país, articulado ao propósito de controle das escolas via avaliações externas e reformas curriculares. Essa apresenta forte rebatimento nas redes públicas de ensino, campo político fértil pelo seu potencial transformador de concepções, ideias, conceitos, valores.

A institucionalização de projetos ultraconservadores como os aqui discutidos coloca em questão o papel da escola e a sua especificidade na formação dos estudantes. O art. 206 da CF de 1988 prevê igualdade de condições para o acesso e a permanência na escola, com liberdade para 
aprender, ensinar, pesquisar e divulgar o pensamento, a arte e o saber, o pluralismo de ideias e concepções pedagógicas.

A defesa, portanto, é pela garantia da autonomia das escolas públicas, na direção do que afirma Freire, (apud BRASIL MEC/SEB, 2004, p. 7):

Tudo o que a gente puder fazer no sentido de convocar os que vivem em torno da escola, e dentro da escola, no sentido de participarem, de tomarem um pouco o destino da escola na mão, também. Tudo o que a gente puder fazer nesse sentido é pouco ainda, considerando o trabalho imenso que se põe diante de nós que é o de assumir esse país democraticamente.

O proposto por Freire só é possível, a partir da tomada de decisões coletivas acerca dos rumos da escola, sistematizadas em um projeto políticopedagógico comprometido com a realidade social, que "manifesta e legitima sua identidade sociopolítica e cultural tendo por base 0 reconhecimento da sociedade onde está inserida a escola" (VEIGA, 2019, p. 45). Para isso, são necessários espaços e tempos que favoreçam aprendizagens em processos pedagógicos de relações e interações pautadas pela liberdade de expressão e pela autonomia pessoal e acadêmica.

A organização da comunidade escolar para o enfrentamento a essa realidade requer vivências democráticas que passam pela possibilidade de o coletivo escolar se posicionar crítica e reflexivamente frente aos desafios a ele impostos para que possa buscar respostas para a sua superação. A escola pública comprometida com a formação humana e que organiza com autonomia o seu trabalho pedagógico é capaz de oportunizar a todos o acesso aos conhecimentos historicamente construídos. Essa escola faz as mediações necessárias entre a educação e o mundo do trabalho em processos dialógicos, críticos e participativos. É essa a escola viável para a construção de uma sociedade melhor para todos.

\section{Sinalizações finais}

Movimentos conservadores como Escola sem Partido e militarização se apresentam como salvação para os problemas da educação básica pública brasileira e, embora distintos no que concerne às proposições por meio de 
projetos, leis, documentos oficiais e textos, compõem um mesmo projeto, ocultando o real intento de exercer o controle eficaz do trabalho pedagógico docente e discente na escola e na sala de aula.

Por um lado, o movimento Escola sem Partido tem forte vinculação política, ideológica e partidária, fundamentado em concepções conservadoras de negação do pluralismo de ideias, de liberdade e de autonomia das escolas para conceberem e gerirem seus projetos políticopedagógicos. Por outro lado, a militarização de escolas públicas substitui os antigos "bedéis" por militares no controle e fiscalização do trabalho docente e de comportamentos dos estudantes, instituindo uma vigilância interna, via controle do espaço e do tempo, de conhecimentos a serem transmitidos, de comportamentos aceitáveis, de corpos a serem disciplinados, da avaliação como mecanismo de controle, entre outros.

Esses movimentos avançam na proporção em que são intensificadas as investidas para desqualificar a escola e seus profissionais por meio da exposição de desempenhos medidos por testes estandardizados. No entanto, as soluções para melhoria da qualidade da educação e do ensino têm sido pouco efetivas, exemplo disso é a não implementação do PNE (2014-2024) que apresenta metas e estratégias para melhoria do sistema público de ensino. No lugar disso, delega-se a militares a responsabilidade pela resolução dos problemas das escolas, na maioria das vezes, causados pela falta de investimentos e políticas sociais.

Nos planos social e pedagógico, gestores e professores são culpabilizados pelos resultados dos desempenhos dos alunos e da escola. $\mathrm{Na}$ mesma direção, estudantes são responsabilizados pela violência que atinge o ambiente escolar. Nesse processo de desresponsabilização do Estado e de redução de investimentos na educação básica pública, esses sujeitos se veem impotentes, até porque as famílias, preocupadas com a segurança de seus filhos, acreditam no "canto da sereia" de que a militarização das escolas é a solução.

As repercussões sobre o projeto político-pedagógico da escola são inúmeras como: a) desmonte do trabalho pedagógico democrático, 
colaborativo e participativo; b) divisão do trabalho no interior da escola com profissionais sem formação pedagógica; c) reforço da cisão entre quem concebe e quem executa o trabalho, corroborando a alienação dos profissionais da educação do e no processo de seu trabalho; d) perda da autonomia docente, pois precisam enquadrar o processo didáticopedagógico no rigor definido por outros; e) formação de sujeitos sem a vivência de auto-organização, submissos às normas e padrões que seguem os rigores dos quartéis.

A temática requer amplo debate para apreensão dos impactos em longo prazo da militarização na organização do trabalho escolar, sobre o trabalho docente, discente e sobre a formação dos jovens estudantes. Para isso, são necessárias pesquisas, algumas sendo desenvolvidas pelas autoras deste artigo. Entretanto, ao mesmo tempo, é preciso criar a resistência política e pedagógica para a defesa da escola pública, gratuita, comprometida com a tarefa educativa de construir sua identidade institucional como espaço de formação humana e de apropriação da cultura, de consciência crítica e voltada para a autonomia de professores e estudantes.

\section{REFERÊNCIAS}

ALVES, G. L. O trabalho didático na escola moderna: formas históricas. Campinas, SP: Autores Associados, 2005.

ANTUNES, R. L. C. Adeus ao Trabalho?: Ensaio sobre as metamorfoses e a centralidade do mundo do trabalho. 7a. ed. Ampl. São Paulo: Cortez; Campinas, SP: Editora da Universidade Estadual de Campinas, 2000.

APPLE, M. W. Educando à direita: mercados, padrões, Deus e desigualdade. São Paulo: Cortez: Instituto Paulo Freire, 2003.

BONDIOLI, A. O projeto pedagógico da creche e a sua avaliação: a qualidade negociada. Campinas: Autores Associados, 2004. 
BRASIL. Constituição da República Federativa do Brasil de 1988. Brasileira, DF: Senado Federal. 2013.

BRASIL. Lei n 9.394, de 20 de dezembro de 1996. Estabelece as diretrizes e bases da educação nacional. Diário Oficial da União, Brasília, DF: 21 jul. 2014.

BRASIL. Lei n 13.005, de 25 de junho de 2014. Aprova o plano Nacional de Educação. - PNE e dá outras providências. Diário Oficial da União, Brasília, DF: 21 jul. 2014.

BRASIL. Ministério da Educação. Secretaria de Educação Básica. NAVARRO, I. P. et al. (Org.). Conselhos Escolares: democratização da escola e construção da cidadania. Brasília: MEC, SEB, 2004. (Programa Nacional de Fortalecimento dos Conselhos Escolares, caderno 1)

BRASIL. Decreto $\mathbf{n}^{\circ}$ 9.665, de 2 de janeiro de 2019. Aprova a Estrutura Regimental e o Quadro Demonstrativo dos Cargos em Comissão e das Funções de Confiança do Ministério da Educação.

BRITO, L. P. P. E.; REZENDE, M. P. Disciplinando a vida, a começar pela escola: a militarização das escolas públicas do estado da Bahia. RBPAE - v. 35, n. 3, p. 844 - 863, set./dez. 2019.

CUNHA, M. I. Os conceitos de espaço, lugar e território nos processos analíticos da formação dos docentes universitários. Revista Educação. Unisinos, v. 12, número 3, set./dez. 2008.

ESPINOZA, B. R. S.; QUEIROZ, F.B. Campanuci. Breve análise sobre as redes da Escola sem Partido. In: FRIGOTTO, G. (org.). Escola "sem" Partido: Esfinge que ameaça a educação e a sociedade brasileira. Rio de Janeiro, RJ: UERJ, LPP. 2017.

FERNANDES SILVA, E.; SILVA, M.A. Militarização das escolas públicas no Distrito Federal: projetos de gestão em disputa. REAe - Revista de Estudos Aplicados em Educação, v. 4, n. 8, jul./dez. 2019.

FERREIRA, L.S. Trabalho pedagógico. In: OLIVEIRA, D.A., et. al. Dicionário trabalho, profissão e condição docente. Belo Horizonte: Faculdade de Educação UFMG, 2010. 
FREITAS, L. C. de. Crítica da Organização do Trabalho Pedagógico e da Didática. 7ed. - Campinas, SP: Papirus, 2005.

FREITAS, L.C.de. Escolas aprisionadas em uma democracia aprisionada: anotações para uma resistência propositiva. Revista HISTEDBR On-line, Campinas, v. 18, n. 4 [78], p. 9-6-926, out./dez. 2018.

FREITAS, L. C. de (2012). Reformadores empresariais da educação: da desmoralização do magistério à destruição do sistema público de ensino, Revista Educação e Sociedade. Campinas, SP: v.33, n.119, p 379-404, abril/junho 2012.

FULLAN, M. e HARGREAVES, A. La escuela que queremos: los objetivos por los cuales vale la pena luchar. $1^{a}$ ed. $1^{a}$ reimp. - Buenos Aires: Amorrortu, 2006.

GUILHERME, A. A.; PICOLI, B. A. Escola sem Partido: elementos totalitários em uma democracia moderna: uma Reflexão a partir de Arendt. Revista Brasileira de Educação. ANPED. v. 23 p.1 a 23. 2018.

HOUAISS, A.; SALLES, V. M. de. Minidicionário Houaiss da Língua Portuguesa. Portuguesa S/C Ltda. Rio de Janeiro: Objetiva, 2001.

JIMENEZ, S.; MENDES SEGUNDO, M.D; RABELO, J. Universalização da educação básica e reprodução do capital: ensaio crítico sobre as diretrizes da política de Educação para Todos. Cadernos de Educação. UFPel. PelotasRS. 2007.

LACÉ, A. L., et al. (2019). Entre a escola e o quartel: a negação do direito à educação. RBPAE: Militarização das escolas públicas no Brasil. v.35, n.3 p.648666, set/dez. 2019.

LIMA, J. A. de. As culturas colaborativas nas escolas: Estruturas, processos e conteúdos. Porto - Portugal: Porto Editora, LDA, 2002.

LOPES, J. J. Reminiscências na paisagem: vozes, discursos e materialidades na configuração das escolas na produção do espaço brasileiro". In: Jader Janer, LOPES; Sônia Marta. CLARETO (orgs.). Espaço e educação: travessias e atravessamentos. Araraquara, JM Editores, p.73-98. 2007. 
MENDONÇA, E. F. Militarização de escolas públicas no DF; a gestão democrática sob ameaça. RBPAE: Militarização das escolas públicas no Brasil. V.35, n.3, p.594-61 1, set/dez. 2019.

MÉSZÁROS, I. A crise estrutural do capital. São Paulo: Boitempo, 2011.

NOGUEIRA J. G. Educação militar no Brasil: um breve histórico. Revista

CAMINE: Caminhos da Educação, Franca, SP, v. 6, n. 1, 2014, p.146-172.

PATTO, Maria Helena Souza. Introdução à psicologia escolar. São Paulo: Casa do Psicólogo, 1997.

POSTIC, Marcel. A relação pedagógica. 2 ed. Coimbra, Portugal: Editora Coimbra Ltda., 1990.

SAVIANI, D. Trabalho e educação: fundamentos ontológicos e históricos.

Revista Brasileira de Educação, v. 12 - n³4, jan./abr. 2007.

SOUZA, L. M. Estado e políticas educacionais: reflexões sobre as teses neoliberais. In: FRANÇA, Robson Luiz de (Org.). Educação e trabalho: políticas públicas e a formação para o trabalho. Campinas, SP: Editora Alínea, 2010.

VEIGA, I. P. A. Educação básica e educação Superior: projeto político pedagógico. $4^{\circ}$ ed. Campinas, SP: Papirus, 2004.

VEIGA, I. P. A. Projeto político pedagógico: currículo, gestão democrática e avaliação. In: VEIGA, I. P. A. Planejamento Educacional: Uma abordagem político-pedagógica em tempos de incertezas. Curitiba, PR: CRV, 2019.

Recebido em: 09 de setembro de 2020

Aprovado em: 05 de outubro de 2020

Publicado em: 23 de novembro de 2020

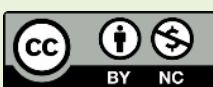

